\title{
Versatile Preparation of Fluorescent Particles Based on Polyphosphazenes: From Micro- to Nanoscale
}

\author{
Jianxiang Zhang, * Liyan Qiu,* Xiaodong Li, Yi Jin, and Kangjie Zhu
}

\begin{abstract}
A
series of intrinsically fluorescent hydrophobic and amphiphilic polyphosphazenes with ethyl tryptophan (EtTrp) and poly(N-isopropylacrylamide) (PNIPAAm) or poly(ethylene glycol) (PEG) as hydrophobic and hydrophilic segments, respectively, are synthesized. Depending on polymer composition and preparation procedure, particles with diameters ranging from micro- to nanoscale can be prepared successfully, which might be used as a visible tracer, both in vitro or in vivo, in drug- or gene-delivery systems, as well as in other biomedical studies such as diagnostic medicine and brain research. Most importantly, in combination with the flexible synthesis and versatile modification of polyphosphazene, this method provides a general protocol to engineer a broad range of fluorescent particles with different properties based on diverse polymers.
\end{abstract}

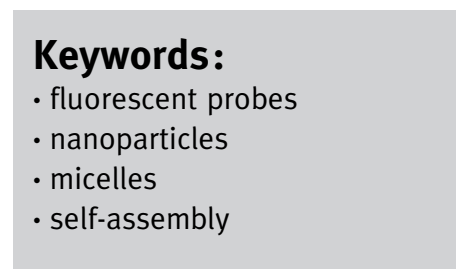

\section{Introduction}

[*] Dr. J. Zhang, Prof. K. Zhu

Key Laboratory of Macromolecule Synthesis and

Functionalization

Ministry of Education

Institute of Polymer Science

Zhejiang University

Hangzhou 310027 (P.R. China)

Fax: (+ 86) 571-879-517-73

E-mail: jxzhang1980@gmail.com

Dr. L. Qiu, Prof. Y. Jin

College of Pharmaceutical Sciences

Zhejiang University

Hangzhou 310068 (P.R. China)

Fax: (+86) 571-882-084-35

E-mail: lyqiu@zju.edu.cn

Dr. X. Li

Affiliated Stomatology Hospital

College of Medicine

Zhejiang University

Hangzhou 310068 (P.R. China)

Dr. J. Zhang

Present address:

Department of Biologic and Materials Sciences University of Michigan

1011 N University Ave, Ann Arbor, MI 48109 (USA)

Supporting information for this article is available on the WWW under http://www.small-journal.com or from the author.
With developments in pharmaceutical science focusing upon the mechanisms of delivery of supramolecular assemblies or macromolecules, scientists have come to realize the limiting nature of the cells' internal barriers, and the requirement for study of spatial and temporal interactions of drug-delivery carriers such as micro- or nanoparticles, liposomes, and micelles with the cell and tissue as well as their intracellular interaction. ${ }^{[1,2]}$ Fluorescence microscopy is a comprehensive tool for investigating many of these aspects in drug-delivery systems or for other biomedical applications. ${ }^{[3,4]}$ For instance, fluorescent objects have been used as in vivo tracers for evaluation of the uptake of nano- and microparticles in the gastrointestinal tract, ${ }^{[5,6]}$ cellular internalization of polymeric micelles, ${ }^{[7]}$ localization of in vivo gene transfection and for brain research. ${ }^{[8-11]}$ Since the fluorescent probes were only physically incorporated into micro- or nanoparticles in many studies, the presence of the fluorescent dyes may influence the surface properties of particles, changing the intrinsic interaction of particles with particular tissues or cells. ${ }^{[12]}$ In addition, the dye entrapped in microparticles may leak into tissue and interfere with the detection of samples of interest. Similarly, there has been little direct evidence provided for the cellular internalization of polymeric micelles themselves due to the presence of physically entrapped probes. ${ }^{[13,14]}$ Recently, polymeric micelles with chemically conjugated fluorescent probes, such as the 
derivatives of rhodamine and fluorescein (FITC), were used to investigate the intracellular uptake and subcellular distribution of micelles. ${ }^{[15-17]}$ However, similar issues need to be addressed in pharmaceutical studies ensuring that a fluorophore probe attached to a drug-delivery system does not affect subcellular distribution or function of vehicles themselves. As pointed out by Moghimi et al., to a certain degree, positively or negatively charged probes might change the nonionic micelles into ionic supramolecular assemblies, which might change the intracellular uptake and distribution of polymeric micelles themselves. ${ }^{[18]}$ Micro- and nanoparticles and micelles with intrinsic fluorescence might circumvent above mentioned problems.

In this study, using poly(dichlorophosphazene) as a scaffold polymer, we synthesized a series of intrinsically fluorescent polymers, either hydrophobic or amphiphilic, by introducing fluorophore ethyl tryptophan (EtTrp) and hydrophilic segment poly (N-isopropylacrylamide) (PNIPAAm) or poly(ethylene glycol) (PEG) into polyphosphazene backbone. Intrinsically fluorescent particles varying from microto nanoscale can be prepared based on these polymers.

\section{Results and Discussion}

\subsection{Copolymer Synthesis}

Poly(dichlorophosphazene) $\left[\mathrm{N}=\mathrm{P}\left(\mathrm{Cl}_{2}\right)\right]_{\mathrm{n}}$ was synthesized by thermal ring-opening polymerization of hexachlorocyclotriphosphazene at $250{ }^{\circ} \mathrm{C}$ in the presence of $5 \% \mathrm{AlCl}_{3} \cdot{ }^{[19]}$ Hydrophobic polyphosphazene (abbreviated as EtTrp-PPP) was synthesized by substituting $\left[\mathrm{N}=\mathrm{P}\left(\mathrm{Cl}_{2}\right)\right]_{\mathrm{n}}$ with excess EtTrp at $60^{\circ} \mathrm{C}$ (Scheme 1). Excess EtTrp was removed by repeated precipitation of polymer from tetrahydrofuran (THF) using diethyl ether that is a poor solvent for polymer, while a good solvent for EtTrp. The polymer thus synthesized is very soluble in common organic solvents, such as chloroform, methyl chloride, THF, dimethylsulfoxide (DMSO), and dimethylformamide (DMF). The Fourier transform infrared (FT-IR) spectrum of EtTrp-PPP shown in Figure S1e of the Supporting Information is similar to that of EtTrp (Figure S1 f). ${ }^{1} \mathrm{H}$ NMR spectrum and the corresponding assignment of EtTrp-PPP homopolymer are presented in Figure S2. ${ }^{31} \mathrm{P}$ NMR results presented in Table S1 shows a main signal at approximately $-0.3 \mathrm{ppm}$ attributable to $-\mathrm{PNH}-$. These results suggested the successful introduction of EtTrp into poly(dichlorophosphazene) backbone. In addition, these results also indicated that only the primary amido group in EtTrp was involved in substitution reaction, while the secondary amido group in themindole ring of EtTrp did not take part in the nucleophilic reaction.

As can be observed from the UV/Vis spectra of EtTrp and EtTrp-PPP shown in Figure S3, the polymer exhibits a spectrum that is similar to that of EtTrp, in which there are two absorbance peaks at 283 and $290 \mathrm{~nm}$, respectively. In addition, UV measurements indicated that $\approx 85 \%$ chlorine was substituted with EtTrp under the reaction conditions employed; this might be a result of the steric-hindrance effect reported by Allcock and co-workers. ${ }^{[20]}$

Amino-terminated oligo-PNIPAAm ( $\mathrm{NH}_{2}$-PNIPAAm) with number-average molecular weight $M_{\mathrm{n}}=$ of 1600 , as determined by $\mathrm{S}$ elemental analysis and titration in nonaqueous solvent, was synthesized by radical polymerization. ${ }^{[21]}$ Our previous study suggested that PNIPAAm-substituted polyphosphazene can be synthesized successfully. ${ }^{[2]}$ This seems to be understandable considering the fact that there is no group with strong steric hindrance near the $\mathrm{NH}_{2}$ group in $\mathrm{NH}_{2}$-PNIPAAm. On the other hand, EtTrp itself exhibits a relatively strong steric hindrance as already mentioned. Consequently, amphiphilic polyphosphazenes with both EtTrp and PNIPAAm as side groups were synthesized by sequential replacement of $\left[\mathrm{N}=\mathrm{P}\left(\mathrm{Cl}_{2}\right)\right]_{n}$ with EtTrp and $\mathrm{NH}_{2}$ PNIPAAm, respectively, to ensure the complete substitution of chlorine atoms in polyphosphazene backbone (Scheme 1). ${ }^{[23]}$ Excess EtTrp and PNIPAAm were removed by repeated precipitation using diethyl ether and dialysis against deionized water, respectively. FT-IR spectra of PNIPAAm and copolymers are illustrated in Figure S1. In addition to the characteristic absorption at $1732 \mathrm{~cm}^{-1}$ due to the carbonyl in EtTrp, peaks at $1648 \mathrm{~cm}^{-1}$ (amide I) and $1547 \mathrm{~cm}^{-1}$ (amide II) could be also clearly observed in the spectra of copolymers, indicating the successful substitution of both EtTrp and PNIPAAm. Furthermore, the intensity of absorption at $1732 \mathrm{~cm}^{-1}$ was enhanced significantly as the EtTrp content in copolymer was increased. ${ }^{1} \mathrm{H}$ NMR spectra and a brief assignment of copolymers containing EtTrp and PNIPAAm are presented in Figure S4. ${ }^{31} \mathrm{P}$ NMR measurement indicated the main peak was near $0 \mathrm{ppm}$ for all these copolymers (Table S1), suggesting the slight difference in chemical shift due to P linked with EtTrp or PNIPAAm. A similar result for polyphosphazenes with ethyl alaninate and ethyl glycinate as side groups was reported by Allcock and co-workers. ${ }^{[24]}$ These results suggested the successful synthesis of copolymers with expected structure. UV/ Vis spectra of these copolymers are shown in Figure S3. In addition to the absorbance

Scheme 1 . Synthesis of intrin
PAAm or PEG as side groups. 
Table 1. Physicochemical properties of polymers.

\begin{tabular}{|c|c|c|c|c|c|c|}
\hline \multirow[t]{3}{*}{ Polymers } & \multirow{3}{*}{\multicolumn{2}{|c|}{$\begin{array}{l}\text { Molar ratio } \\
\text { PNIPAAm or PEG } \\
y\end{array}$}} & \multirow[t]{3}{*}{$M_{\mathrm{w}}$} & \multirow[t]{3}{*}{$M_{\mathrm{n}}$} & \multirow{3}{*}{$\begin{array}{c}\text { CAC/ } \\
(g / L)^{[a]}\end{array}$} & \multirow[t]{3}{*}{ Relative quantum yield $(\Phi)^{[\mathrm{b}]}$} \\
\hline & & & & & & \\
\hline & & & & & & \\
\hline EtTrp & - & - & - & - & - & 0.176 \\
\hline PNIPAAm & - & - & - & 1600 & - & - \\
\hline EtTrp-PPP & 1.70 & 0.00 & 15000 & 6000 & - & 0.156 \\
\hline PNIPAAm/EtTrp-PPP-1 & 1.21 & 0.79 & 27000 & 16900 & 0.022 & 0.097 \\
\hline PNIPAAm/EtTrp-PPP-2 & 1.13 & 0.87 & 39000 & 31000 & 0.058 & 0.116 \\
\hline PNIPAAm/EtTrp-PPP-3 & 0.79 & 1.21 & 41000 & 32000 & 0.102 & 0.145 \\
\hline PEG350/EtTrp-PPP & 1.47 & 0.53 & 26000 & 18000 & 0.020 & 0.124 \\
\hline PEG1100/EtTrp-PPP & 1.57 & 0.43 & 37000 & 28000 & 0.022 & 0.118 \\
\hline PEG2000/EtTrp-PPP & 1.30 & 0.70 & 59000 & 46000 & 0.083 & 0.132 \\
\hline
\end{tabular}

[a] Determined by fluorescent probe technique; [b] Tryptophan was used as standard.

at 283 and $290 \mathrm{~nm}$ due to the EtTrp group, a new peak at about $400 \mathrm{~nm}$ can be also observed for these copolymers. At present, we can not assign this absorbance, and further study needs to be carried out to address this issue. The molar content of EtTrp in copolymers was determined by UV measurements at $283 \mathrm{~nm}$ with the calibration curve established by concentration-dependent absorbance of EtTrp at $283 \mathrm{~nm}$ in the same solvent, and the corresponding results are presented in Table 1. Other physicochemical properties of copolymers are also listed in the same table.

As can be seen from many studies on polymeric assemblies used as imaging agents or drug-delivery systems, poly(ethylene glycol) (PEG) is probably the most commonly used hydrophilic block to synthesize amphiphilic copolymers, due to its strong hydration and high conformational flexibility, its low toxicity, and weak immunogenecity. ${ }^{[25-27]}$ This is especially true for nanocarriers that require intravenous administration. Consequently, in addition to PNIPAAm, we synthesized intrinsically fluorescent amphiphilic polyphosphazenes with PEG as the hydrophilic segment. Exactly the same synthesis and purification procedures were adopted to synthesize amphiphilic polyphosphazenes with PEG of different molecular weights $(350,1100,2000)$ as hydrophilic segments. FT-IR and ${ }^{1} \mathrm{H}$ NMR spectra and the related assignment of PEG-containing copolymers are illustrated in Figure S5 and S6. ${ }^{31} \mathrm{P}$ NMR results are presented in Table S1. Similar to that of PNIPAAm-containing copolymers, an absorbance at $400 \mathrm{~nm}$ was also observed for copolymers with PEG as hydrophilic segment (Figure S7). The intensity of this absorbance is proportional to copolymer concentration. The molar content of EtTrp in copolymer, as quantified by UV methods, is presented in Table 1. However, care should be taken when comparing the molecular weight of amphiphilic copolymers with PNIPAAm and PEG hydrophilic segments since these two series of copolymers were synthesized using poly(dichlorophosphazene) of different batches.

\subsection{Polymer Fluorescence}

Tryptophan, an intrinsic fluorophore with high quantum yield, is usually used as a probe for protein structural inves- tigation; $;^{[28]}$ it has a major emission peak $\left(\lambda_{\text {emm }}\right)$ at $340 \mathrm{~nm}$ corresponding to an excitation wavelength $\left(\lambda_{\text {exc }}\right)$ at $280 \mathrm{~nm}$ and a Stokes shift $\Delta \lambda=60 \mathrm{~nm}$. Tryptophan ester, tryptophan octyl ester for instance, was also used as the hydrophobic fluorescence probe for the study of membrane proteins, liposomes, and micelles. ${ }^{[29-31]}$ A red-shift effect was observed for both excitation and emission spectra of tryptophan ethyl ester (EtTrp), as shown in the isometric projections of the emission-excitation data matrix (EEM) of tryptophan and EtTrp (Figure $1 \mathrm{a}$ and $\mathrm{b}$ ). The $\lambda_{\mathrm{emm}}$ was shifted to $500 \mathrm{~nm}$ with $\lambda_{\text {exc }}=410 \mathrm{~nm}$, and the Stokes shift was increased to about $90 \mathrm{~nm}$; this is consistent with literature in which a very large Stokes shift was also found for tryptophan analogues. ${ }^{[32]}$ This suggests that EtTrp-based polymers might be excited by visible light, blue or green light for instance, and radiate visible light concomitantly. On the other hand, although tryptophan residue is widely distributed in many proteins, its short excitation wavelength (UV region) limits fluorescence imaging in many studies. This is why many studies concerning fluorescence imaging were carried out by fluorescent-probe-labeling techniques, fluorescein 5(6)-isothiocyanate (FITC) or green fluorescent protein (GFP) labeling for instance. ${ }^{[12,33-39]}$

By introducing the fluorophore group EtTrp into polyphosphazene backbone, intrinsically fluorescent polymers were synthesized. Fluorescent properties of the synthesized copolymers were investigated by fluorescence spectrophotometry. The isometric projections of the EEM of EtTrpsubstituted homopolymer (EtTrp-PPP) and amphiphilic copolymers (PNIPAAm/EtTrp-PPPs) containing PNIPAAm are shown in Figure 1. EtTrp-PPP exhibits a fluorescent profile similar to that of EtTrp. As for amphiphilic copolymers, in addition to the EtTrp related peak, another peak at lower wavelength appeared, which was dramatically enhanced with decreased EtTrp substitution (Figure 1d-f). Since almost no significant fluorescence was observed for amphiphilic polyphosphazenes with ethyl glycinate or ethyl 4-aminobenzoate and PNIPAAm as hydrophobic and hydrophilic substitutes, respectively (Figure S8), the peak at lower-excitation emission could be attributed to EtTrp groups locating in different microenvironments in the polymer backbone. As reported, the emission spectra of tryptophan residues are highly dependent on their environment in many pro- 
(a)

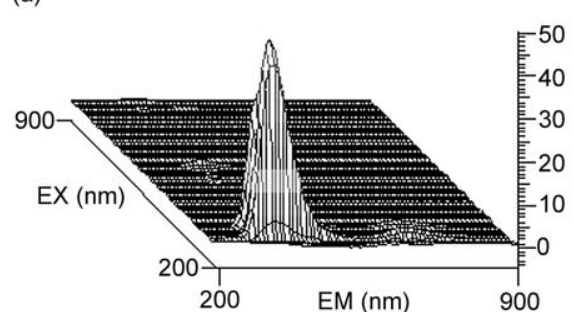

(d)

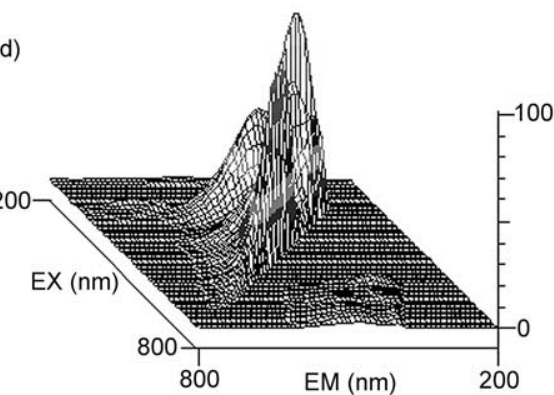

(b)
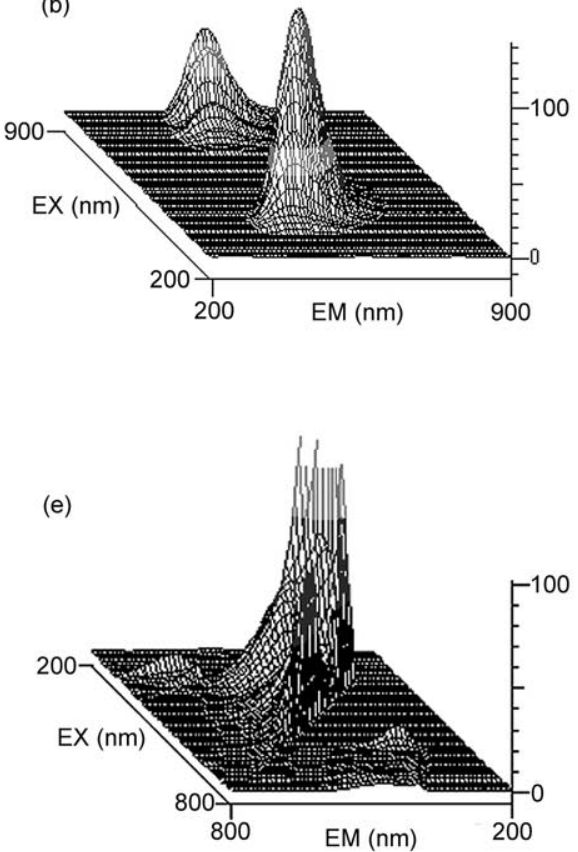
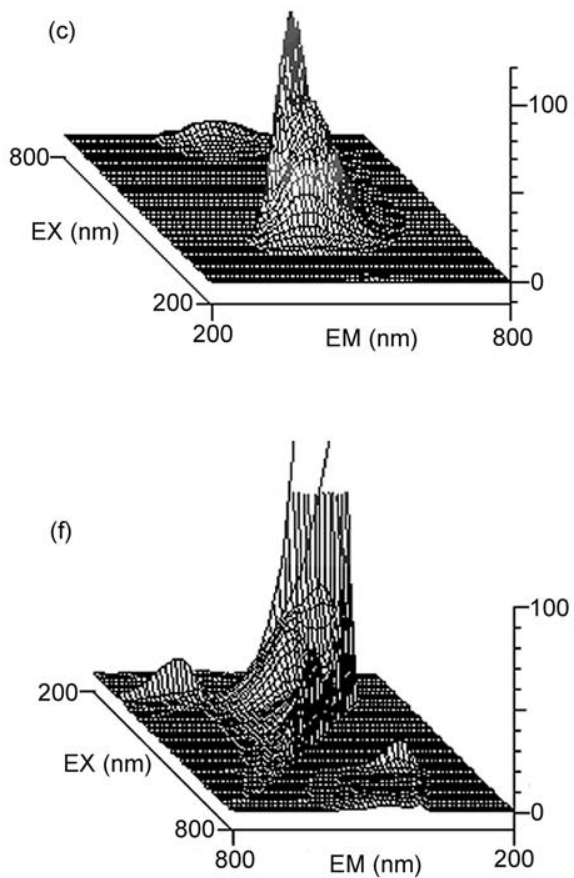

Figure 1. The isometric projections of the EEM of a) tryptophan, saturated in DMF; b) EtTrp, c) EtTrp-PPP, d) PNIPAAm/EtTrp-PPP-1, e) PNIPAAm/ EtTrp-PPP-2, and f) PNIPAAm/EtTrp-PPP-3; $10 \mathrm{mg} \mathrm{mL}^{-1}$ in DMF.

teins. For example, the emission spectra of tryptophan residues in human serum albumin and azurin are blue shifted relative to that of tryptophan in water, which might be due to the shielding of the tryptophan residues from the aqueous phase by the protein itself. ${ }^{[40]}$ As for the copolymers studied here, the distribution of EtTrp in copolymer should have some influence on fluorescent characteristics, and this structure-fluorescence correlation will be elucidated in our future research. In aqueous media, no EtTrp-related fluorescent peaks could be observed for all the amphiphilic copolymers as a result of strong Tyndall scattering and Rayleigh scattering since polymeric micelles were assembled in this case.

As for the emission at about $400 \mathrm{~nm}$ with an excitation at $800-900 \mathrm{~nm}$, it can be attributed to two-photon excitation. Multiphoton excitation (MPE) refers to the simultaneous absorption of two or more long-wavelength photons to excite a fluorophore to the first excited singlet state. ${ }^{[1,42]}$ Indeed, two- and three-photon excitation processes have already been observed for tryptophan derivatives and proteins containing tryptophan residues ${ }^{[43,44]}$ In the case of the copolymers studied here, they exhibit a shift in the absorption and excitation spectra between one- and two-photon process, as shown in Figure 1. This phenomenon has been also observed for tryptophan and tyrosine residues in proteins. ${ }^{[45,46]}$

The isometric projections of the EEM of PEG containing copolymers are illustrated in Figure 2 . In addition to the strong excitation-emission peak due to EtTrp, relatively significant two-photon excitation could be observed in the isometric projection images of PEG-based copolymers (Figure 2) compared with that of PNIPAAm-containing co- polymers (Figure 1d, e, and f). The different microenvironment for EtTrp groups might be partly responsible for this result, and the MPE of PNIPAAm containing copolymers might be partly quenched by PNIPAAm chains, since it has been reported that the fluorescence of tryptophan residues in proteins could be quenched by acrylamide. ${ }^{[47]}$

The relative quantum yields of EtTrp and various polymers were determined using tryptophan $\left(\Phi_{\operatorname{Trp}}=0.14\right)$ as standard, and the results are listed in Table 1 . The $\Phi$ of EtTrp in Table 1 is significantly larger than that obtained by Eftink and co-workers, ${ }^{[32]}$ which should be due to the different solvents employed. DMF was used as the solvent for all the samples to determine quantum yield in this study, whereas aqueous solution ( $\mathrm{pH} 5.0)$ was used by Eftink et al. ${ }^{[32]}$ The dramatic effect of solvent and $\mathrm{pH}$ on the quantum yield of tryptophan analogues has been well documented. ${ }^{[32,48]}$ The quantum yield of polymers containing EtTrp is smaller than that for EtTrp itself. In addition, for PNIPAAm containing amphiphilic copolymers, the quantum yield increased as the EtTrp content decreased. These differences might be also attributed to the specific architecture of individual polymer. As reported by Singh et al., the microenvironment has significant influence on the quantum yield of tryptophan and its derivatives. ${ }^{[48]}$

\subsection{Preparation and Characterization of Microparticles Based on EtTrp-PPP}

Microspheres based on EtTrp-PPP were prepared by an oil-in-water emulsion solvent-evaporation technique. ${ }^{[49]}$ The average particle size (by number) of microspheres, as deter- 

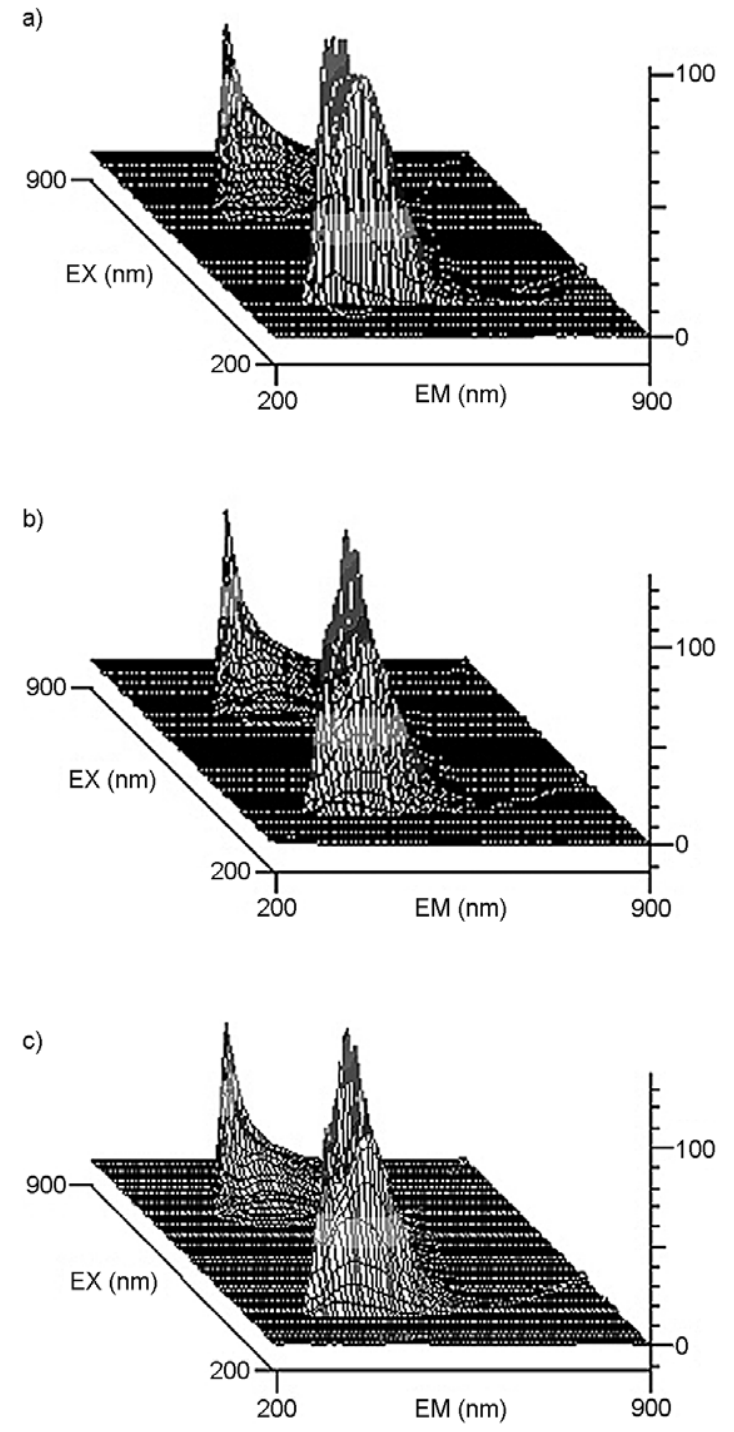

Figure 2. The isometric projections of the EEM of a) PEG350/EtTrpPPP, b) PEG1100/EtTrp-PPP, and c) PEG2000/EtTrp-PPP.

mined by laser particle-size analyzer, was about $35 \mu \mathrm{m}$. Confocal laser scanning microscopy (CLSM) was employed to evaluate the fluorescence character of these microspheres. As show in Figure $3 \mathrm{a}$ and $\mathrm{b}$, bright green and red microspheres could be observed with the excitation at 488 and $543 \mathrm{~nm}$, respectively, and an overlay image is bright yellow (Figure 3c). This result suggests that microspheres based on polyphosphazene homopolymer containing EtTrp can be excited by visible light (blue or green light for instance) and radiate bright fluorescence. Since through sophisticated techniques such as the emulsion solvent-evaporation method adopted in this study and the coacervation method, microparticles with particle size ranging from hundreds of nanometers to several millimeters can be successfully prepared. ${ }^{[49,50]}$ Considering the excellent biodegradability and biocompatibility of polyphosphazenes with amino acid esters as side groups, as studied by Allcock's group and other researchers, ${ }^{[51-55]}$ a novel type of biodegradable and biocompatible "visible microparticles" of various sizes can be produced based on intrinsically fluorescent polymer EtTrp-PPP.

As a fluorescence tracer polymer, it is very important to maintain its structure integrity for an appropriate time period to ensure the related study can be performed successfully and to avoid artifact due to polymer degradation. Consequently, it is necessary to investigate the degradability of fluorescent polymer EtTrp-PPP. In vitro degradation study on EtTrp-PPP based microspheres was carried out in $0.1 \mathrm{~m}$ PBS ( $\mathrm{pH} 7.4$ ). Figure 4 shows the changes in molecular weight with degradation time. Clearly, almost no change in molecular weight was observed within the first two months. A slight decrease in molecular weight was found after degradation for about 80 days. During this time, $M_{\mathrm{w}}$ was decreased from 15 to $\approx 14 \mathrm{kDa}$. However, even after 6 months of degradation, $M_{\mathrm{w}}$ decrease was still not significant, with a reduction of $\approx 3 \mathrm{kDa}$. In addition, the fluorescence of microspheres was also traced during degradation study using fluorescence microscopy. As illustrated in the inset images in Figure 4, bright green microspheres could be observed during the whole degradation experiment, suggesting almost no fluorescence loss in this process, which is consistent with $M_{\mathrm{w}}$ determination.

\subsection{Critical Association Concentration (CAC) of Amphiphilic Copolymers in Aqueous Solution}

As a measure of the micellization onset of amphiphilic copolymer in aqueous solution, CAC is a very important parameter for copolymers. Steady-state fluorescence techniques using pyrene as a probe is probably the most widely used method to determine the CAC of amphiphilic copolymers. As shown in Figure S10, since the fluorescence of copolymer itself has no significant influence on the excitation (emission at $390 \mathrm{~nm}$ ) and emission (excitation at $339 \mathrm{~nm}$ ) spectra of pyrene, a probe technique was also employed to determine the apparent CAC of copolymers of interest. As reported by Wilhelm et al., the $I_{338} / I_{333}$ ratio from pyrene excitation spectrum is sensitive to an onset of micellization, which takes the value characteristic of pyrene in water at low polymer concentrations, while at high concentrations it takes the value of pyrene in the hydrophobic microdomains. The value of the $I_{338} / I_{333}$ ratio increased significantly with the transfer of pyrene molecules from a polar microenvironment to a more hydrophobic one. As seen in Figure 5, the plots of $I_{338} / I_{333}$ versus $\log \mathrm{C}$ are flat at low copolymer concentrations and sigmoidal in the crossover region. CAC was determined from the intersection of straight-line segments, drawn through the points at the lowest polymer concentrations, going through the points on the rapidly rising part of the plot. CACs calculated for various copolymers are listed in Table 1. As can be found for PNIPAAm-containing copolymers, the value of CAC decreased significantly as the molar content of EtTrp group increased, which is consistent with our previous results for amphiphilic polyphosphazenes with ethyl glycinate and PNIPAAm as side groups. ${ }^{[22]}$ 

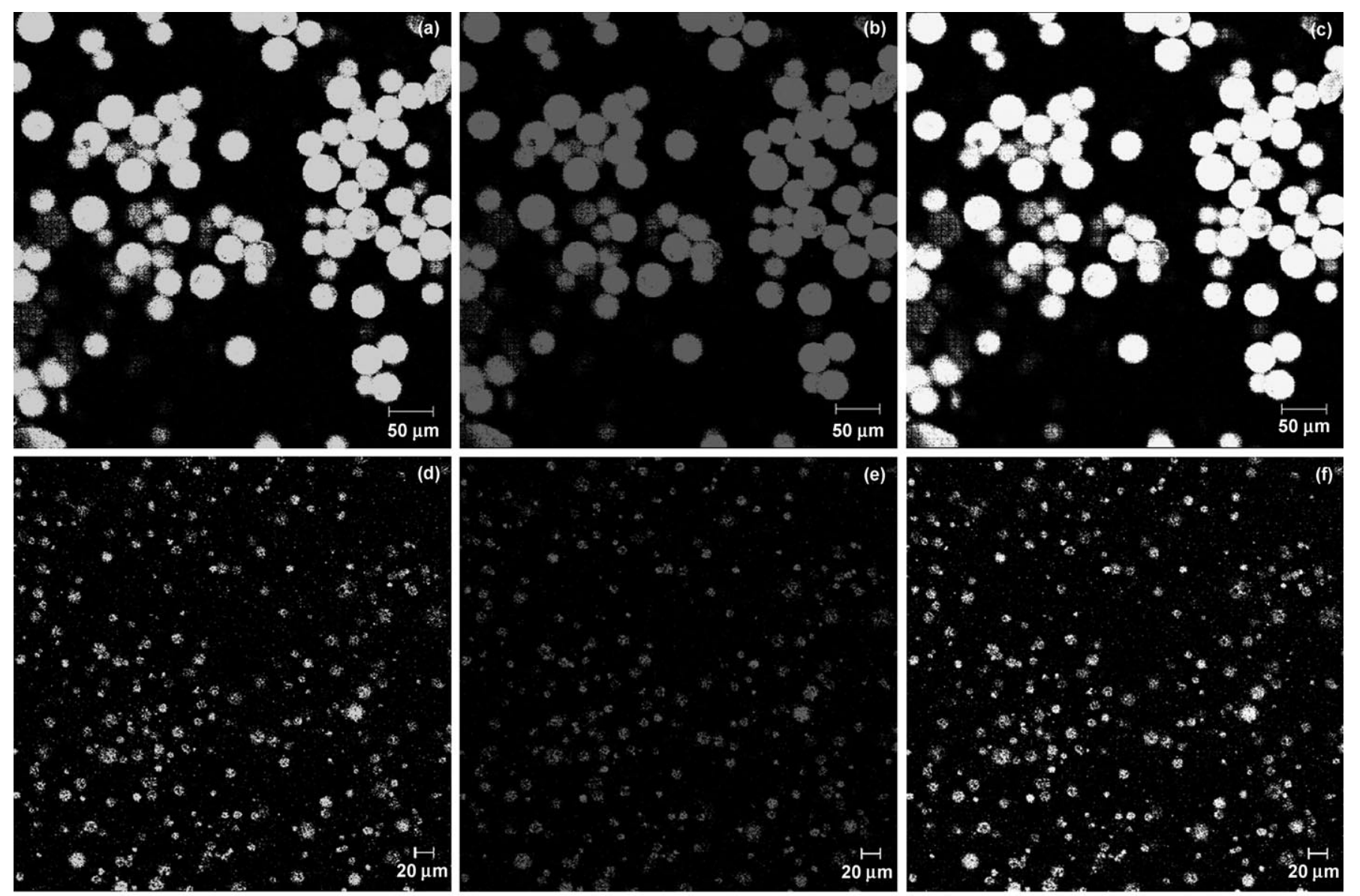

(g)

(h)

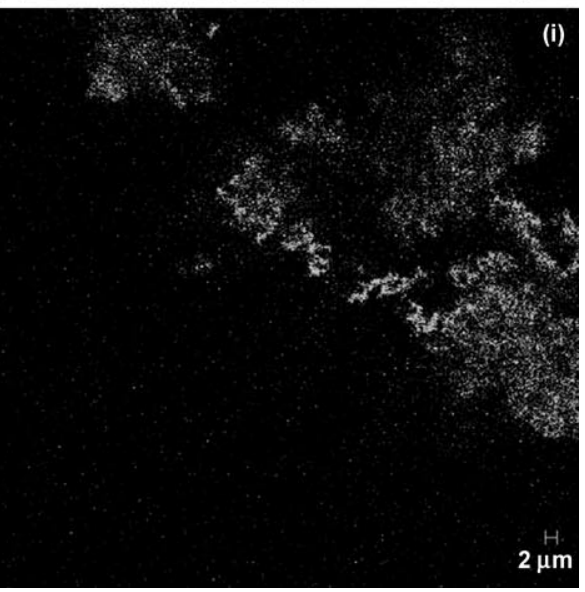

Figure 3. CLSM images of a, b) EtTrp-PPP-based microspheres; c) an overlay of (a) and (b), scale bar $=50 \mu \mathrm{m}$; d, e) PNIPAAm/EtTrp-PPP-1-based assemblies prepared by dialysis, THF as solvent; $f$ ) an overlay of (d) and (e), scale bar $=20 \mu \mathrm{m}$; g) PNIPAAm/EtTrp-PPP-1 -based assemblies prepared by dialysis, DMSO as solvent; h) PNIPAAm/EtTrp-PPP-2-based assemblies prepared by dialysis at $30^{\circ} \mathrm{C}$, DMSO as solvent; i) assemblies at $37^{\circ} \mathrm{C}$; the same sample as (h) was employed.

\subsection{Assembled Nanoparticles from Amphiphilic Copolymers (PNIPAAm/EtTrp-PPPs)}

A dialysis method was adopted to prepare polymeric assemblies based on PNIPAAm-containing copolymers that are not soluble in water, including PNIPAAm/EtTrp-PPP-1 and -2 . Various organic solvents were used to modulate the particle size and morphology of assemblies based on our previous results. ${ }^{[23,56]}$ A set of TEM images of PNIPAAm/
EtTrp-PPP-1-based nanoparticles prepared by dialysis using $\mathrm{N}$, N-dimethylformamide (DMF), dimethylsulfoxide (DMSO), N, N-dimethylacetamide (DMAc), methanol, N, $\mathrm{N}$-dimethylpropionamide (DMP), and tetrahydrofuran (THF), are illustrated in Figure 6. Depending on dialysis solvent, well-defined spherical nanoparticles with significantly different sizes can be prepared. The average particle size for nanoparticles prepared using DMF, DMSO, DMAc, and methanol was $60,71,85$, and $450 \mathrm{~nm}$, respectively. In 


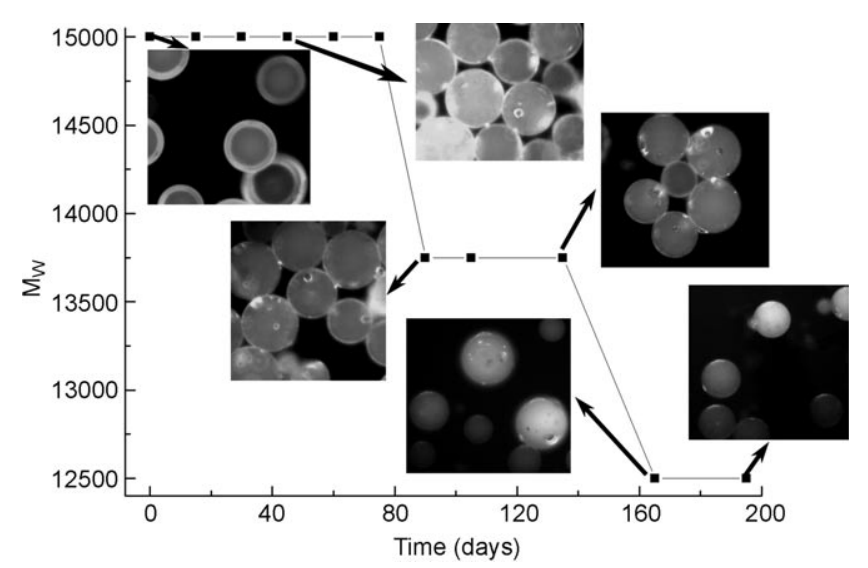

Figure 4. Changes in weight-averaged molecular weight of EtTrp-PPP as a function of degradation time. Inset images show the green fluorescence of EtTrp-PPP-based microspheres at various time points during in vitro degradation.

addition, wormlike micelles were obtained when DMP was employed as solvent. As evidenced by Discher's group most recently, filament-like micelles, known as filomicelles by authors, exhibited significantly longer circulation time compared with their spherical counterparts after intravenous in- jection in rodents. ${ }^{[57]}$ Due to the same reason, these wormlike micelles might be also long-circulating vehicles, which might be a potential agent for blood-pool imaging considering the possibility of extending the imaging window. However, these nanoparticles can not be observed directly by fluorescent microscopy, since the lateral $(x-y)$ resolution of the confocal microscope with a high numerical aperture oil immersion objective is about $250 \mathrm{~nm} \cdot{ }^{[58,59]}$ As shown in Figure $3 \mathrm{~g}$, only scattered points from background scattering were observed. Interestingly, as can be seen from Figure $6 \mathrm{f}$, large vesicles were obtained by dialysis of PNIPAAm/ EtTrp-PPP-1 using THF as solvent, and the sedimented particles could be easily observed by CLSM (Figure $3 \mathrm{~d}$, e, and f). Green and red fluorescence could be observed when it was excited at 488 and $543 \mathrm{~nm}$, respectively, and an overlay image showed a yellow picture.

As for PNIPAAm/EtTrp-PPP-2, nanoparticles with diameter less than $100 \mathrm{~nm}$ could be produced when the preparation temperature was near or above $32^{\circ} \mathrm{C}$. At temperatures below $32^{\circ} \mathrm{C}$, however, only networklike assemblies were formed. ${ }^{[23]}$ In addition, the nanoparticles formed at higher temperature were also beyond the resolution of CLSM (Figure $3 \mathrm{~h}$ ). However, as the temperature of the sample stage increased above the lower critical solution temperature (LCST) of PNIPAAm, interparticle aggregates resulted from the phase transition of PNIPAAm shell, were clearly observed by CLSM (Figure 3i). A similar phenomenon was observed for PNIPAAm/EtTrp-PPP-3based assemblies. These results further suggest that the introduction of fluorophore group EtTrp will provide amphiphilic polyphosphazenes with intrinsic fluorescence, which can be easily detected by fluorescence spectrophotometry or microscopy.

\subsection{Assembled Hybrid Nanoparticles Based on EtTrp-PPP and PNIPAAm/EtTrp-PPPs}

In addition to the assembly of amphiphilic copolymers in aqueous solution, nanoparticles were also prepared by dialysis of the mixture of EtTrp-PPP and PNIPAAm/EtTrp-PPP-2 using DMF as solvent. Since both amphiphilic copolymer and homopolymer have an EtTrp side group, we could expect good compatibility between
Figure 5. Plots of the intensity ratios $I_{338} / I_{333}$, which were obtained from the excitation spectra of pyrene in aqueous solutions with amphiphilic copolymer of various concentrations, as a function of $\log C$; a) PNIPAAm/EtTrp-PPP-1, b) PNIPAAm/EtTrp-PPP-2, c) PNIPAAm/EtTrp-PPP-3, d) PEG350/EtTrp-PPP, e) PEG1100/EtTrp-PPP, and f) PEG2000/EtTrp-PPP. 

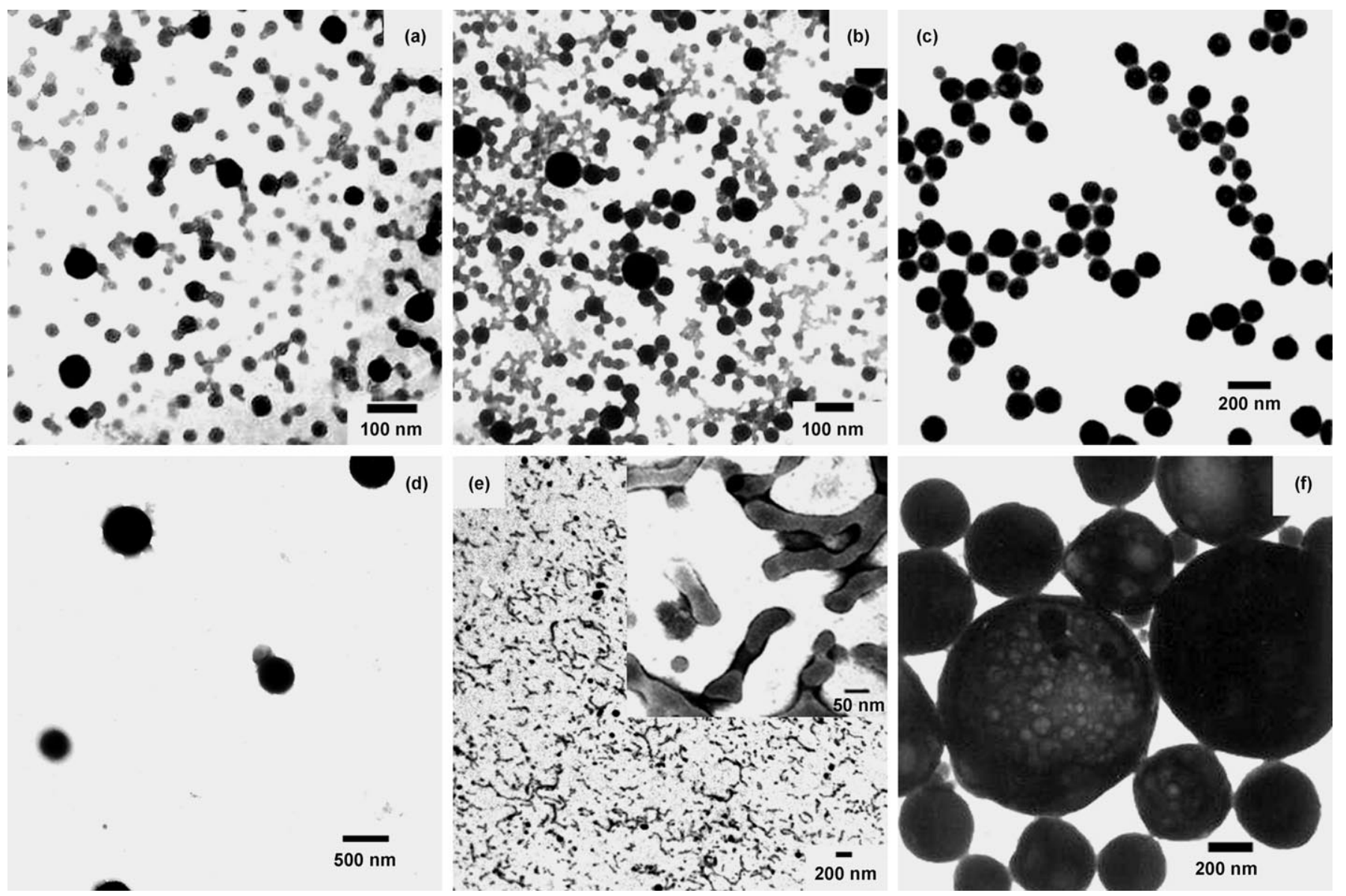

Figure 6. Polymeric assemblies of PNIPAAm/EtTrp-PPP-1 prepared by dialysis using various organic solvents: a) DMF, b) DMSO, c) DMAc, d) methanol, e) DMP, and f) THF.

the core of micelle based on PNIPAAm/EtTrp-PPP and EtTrp-PPP homopolymer, which is prerequisite for the formation of hybrid micelles. Figure 7 shows TEM images of hybrid assemblies based on PNIPAAm/EtTrp-PPP-2 and EtTrp-PPP of various weight ratios. For a formulation of $0.5 / 10$, both spherical nanoparticles and networklike assemblies were observed (Figure 7a). The latter is a characteristic structure for assemblies based on pure PNIPAAm/EtTrpPPP-2 at lower temperature, as studied in our previous work. ${ }^{[23,60]}$ This suggested that the mass of homopolymer is insufficient to completely form spherical assemblies. As the weight ratio of EtTrp-PPP to PNIPAAm/EtTrp-PPP-2 increased to 2.5/10, spherical particles with an average size of $650 \mathrm{~nm}$ were obtained, as shown in Figure $7 \mathrm{~b}$. Further increase in EtTrp-PPP content, however, results in the aggregation of hybrid assemblies, as illustrated in Figure $7 \mathrm{c}$. For the observation of this type of assemblies through CLSM, the settled particles based on the formulation of 2.5/10 were employed. As can be seen from Figure 8, bright green and red fluorescence was observed when excited at 488 and $453 \mathrm{~nm}$, respectively. These results indicate that fluorescent nanoparticles can be also engineered from homopolymer and amphiphilic copolymer of appropriate weight ratio by the dialysis method.

\subsection{Assembled Micelles Based on Amphiphilic Copolymer with EtTrp and PEG as Side Groups}

Micelles based on PEG350/EtTrp-PPP and PEG1100/ EtTrp-PPP were also prepared by dialysis using various organic solvents. As shown in Figure 9, PEG350/EtTrp-PPPderived polymeric micelles with a mean size of 320,180 , and $60 \mathrm{~nm}$ were prepared when DMF, acetone, and DMAc employed as solvent, respectively. As for PEG1100/EtTrpPPP, assemblies with a mean size of 66 and $45 \mathrm{~nm}$ could be prepared using DMF and DMAc as solvent, respectively (Figure 9d and e). In the case of PEG2000/EtTrp-PPP, assemblies were obtained by directly dissolving copolymer into water, and micelles of $50 \mathrm{~nm}$ were thus prepared (Figure $9 \mathrm{f}$ ). These results suggested that depending on the type of dialysis solvent or copolymer composition, sphere-shaped nanoparticles ranging from hundreds to tens of nanometers could be obtained from PEG containing amphiphilic copolymers. On the one hand, for a specific copolymer, particle size can be modulated by dialysis organic solvent (Figure $9 \mathrm{a}-\mathrm{e}$ ), while on the other hand, size of assemblies can be controlled by the chain length of hydrophilic segment (Figure 9a, d, and f).

Due to the same resolution limitation, assemblies shown in Figure 9 can not be directly observed through CLSM. 


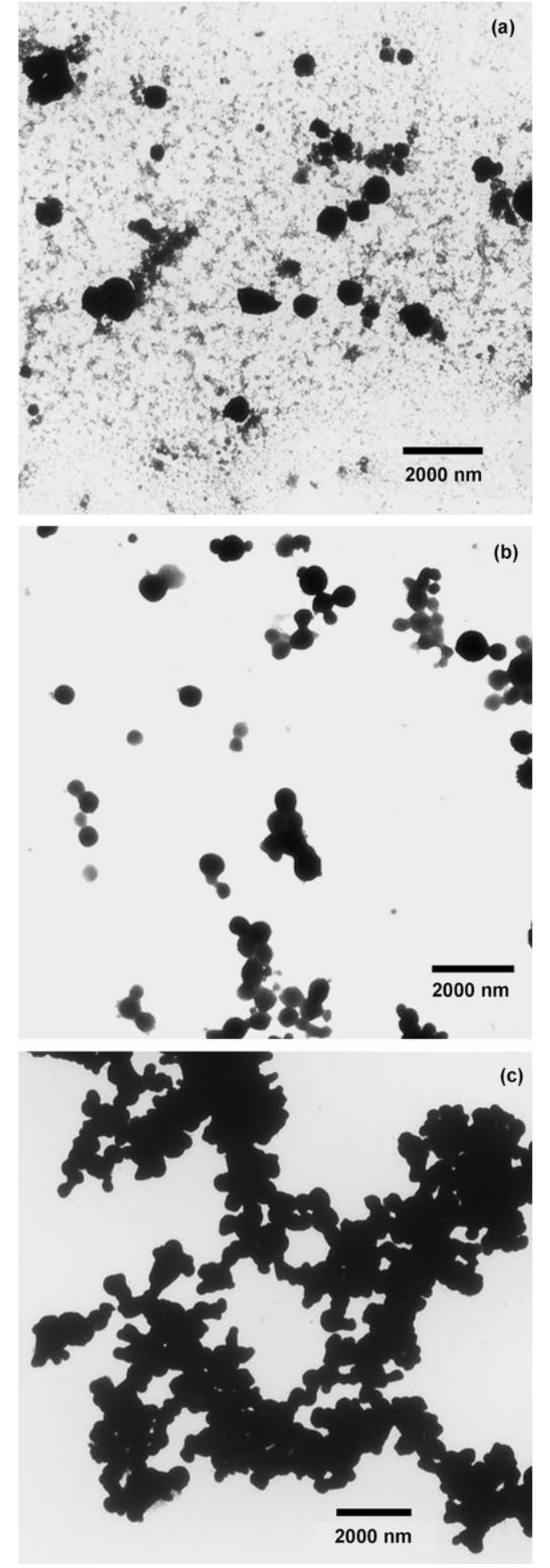

Figure 7. TEM images of hybrid assemblies based on EtTrp-PPP and PNIPAAm/EtTrp-PPP-2 with different weight ratios: a) 0.5/10, b) $2.5 /$ 10, and c) 5.0/10.

However, for polymeric assemblies from PEG350/EtTrpPPP using DMF as dialysis solvent, the settled aggregates can be observed by CLSM since they have relatively larger
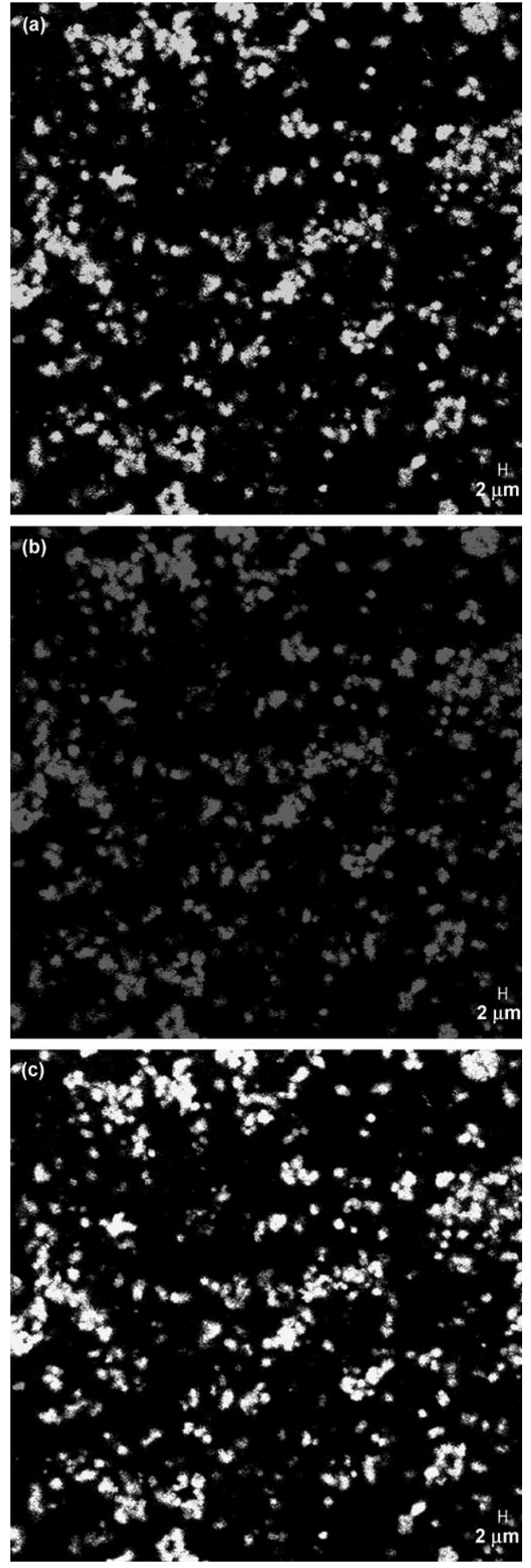

Figure 8. CLSM images of settled hybrid assemblies based on EtTrpPPP and PNIPAAm/EtTrp-PPP-2 with the weight ratio of 2.5/10, which were prepared by the dialysis method using DMF as organic solvent: a) excited at $488 \mathrm{~nm}, \mathrm{~b}$ ) excited at $543 \mathrm{~nm}$, and c) an overlay of (a) and (b).

particle size. As shown in Figure 10, strong green and red emission can be observed directly. 


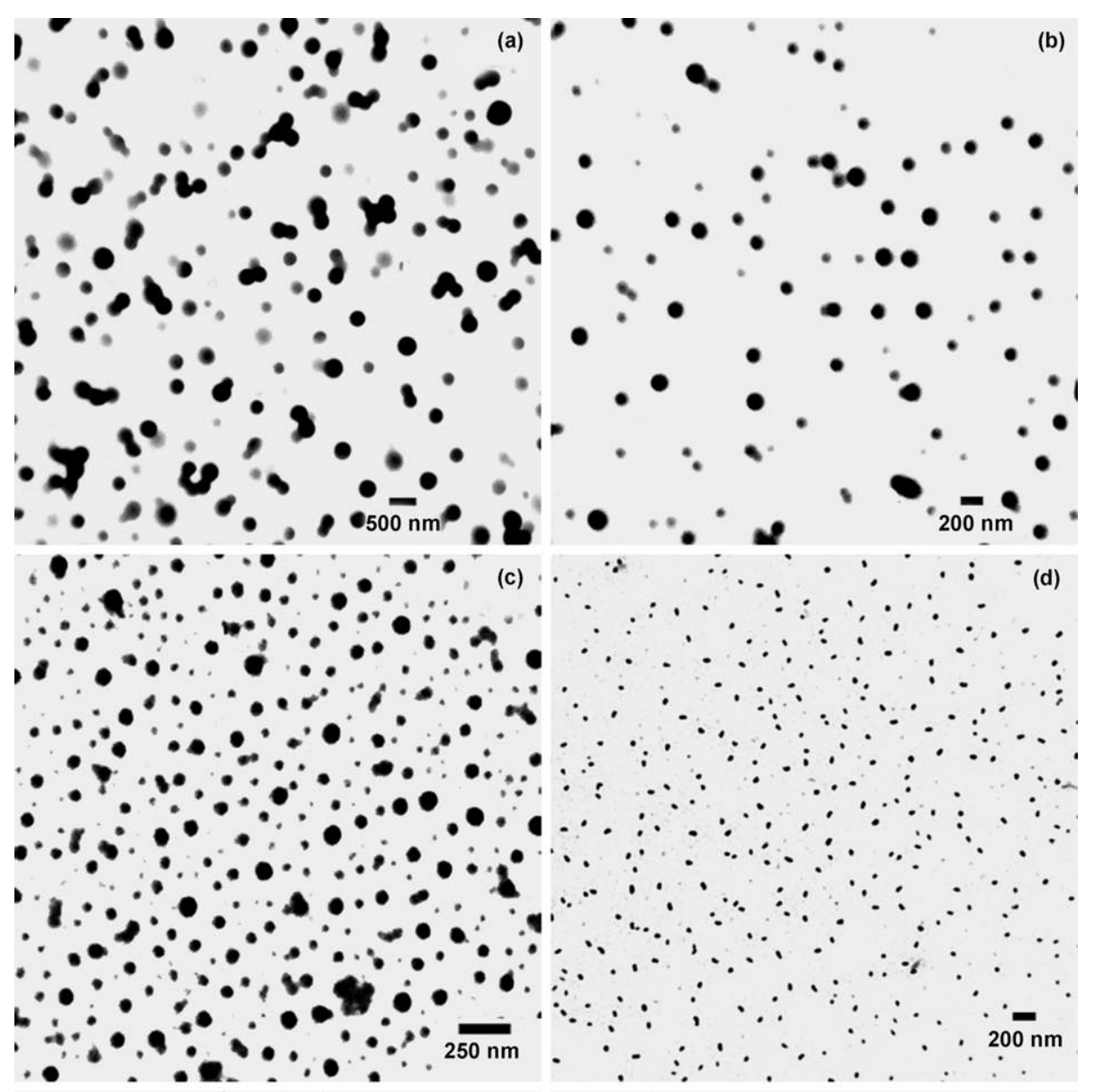

(e)

Figure 9. TEM images of assemblies based on PEG containing copolymers: a) PEG350/EtTrp-PPP, DMF; b) PEG350/EtTrp-PPP, acetone; c) PEG350/EtTrp-PPP, DMAc; d) PEG1100/EtTrp-PPP, DMF; e) PEG1100/ EtTrp-PPP, DMAc, and f) PEG2000/EtTrp-PPP.

\subsection{Intracellular Uptake of Micelles Based on PEG2000/ EtTrp-PPP}

As demonstrated by many studies, polymeric micelles are water-soluble biocompatible nanocarriers, which have great potential for delivering bioactive substances, such as hydrophobic drugs, metal complexes, photosensitizers, genes, and siRNA. ${ }^{[61]}$ Consequently, an understanding of the cellular distribution of polymeric micelles is essential to (f)

achieving selective delivery of drugs at the subcellular level. As a preliminary study, we selected human osteosarcoma cell line MG-63 to investigate the uptake and cellular distribution of assemblies based on PEG2000/ EtTrp-PPP. Figure 11 shows microscopy images of MG-63 cells that were incubated in culture medium with or without polymeric micelles based on PEG2000/EtTrp-PPP. The fluorescent image in Figure $11 \mathrm{~b}$ indicates the cellular distribution of polymeric assemblies. The absence of green fluorescence in the nucleus of MG-63 cells as illustrated by the white arrows reveals the localization of micelles in cytoplasm organelles but not in the nucleus. This result is consistent with that reported recently by Savić et al., ${ }^{[17]}$ which was based on a study using tetramethylrhodamine-5-carbonyl azide labeled amphiphilic copolymer polycaprolactone- $b$ poly (ethylene oxide). On the other hand, for control cells in culture medium without amphiphilic copolymer, no fluorescence is observed (Figure 11d). As for the internalization of micelles, it should be mainly mediated by endocytosis as reviewed by Torchilin, ${ }^{[3]}$ which is similar to the intracellular uptake of other nanoparticles. ${ }^{[1]}$

\section{Conclusions}

In summary, a series of intrinsically fluorescent polyphosphazenes has been synthesized. Depending on polymer composition and preparation procedure, particles varying from micro- to nanoscale can be engineered, which might be used as potential visible tracers in vitro or in vivo, in drug or gene-delivery systems, and in other biomedical studies such as diagnostic medicine and brain research. Most importantly, depending on polymer structure a wide range of fluorescent polymers can be produced with proper molecular design. Intracellular uptake of "visible micelles" based on PEG-containing amphiphilic 

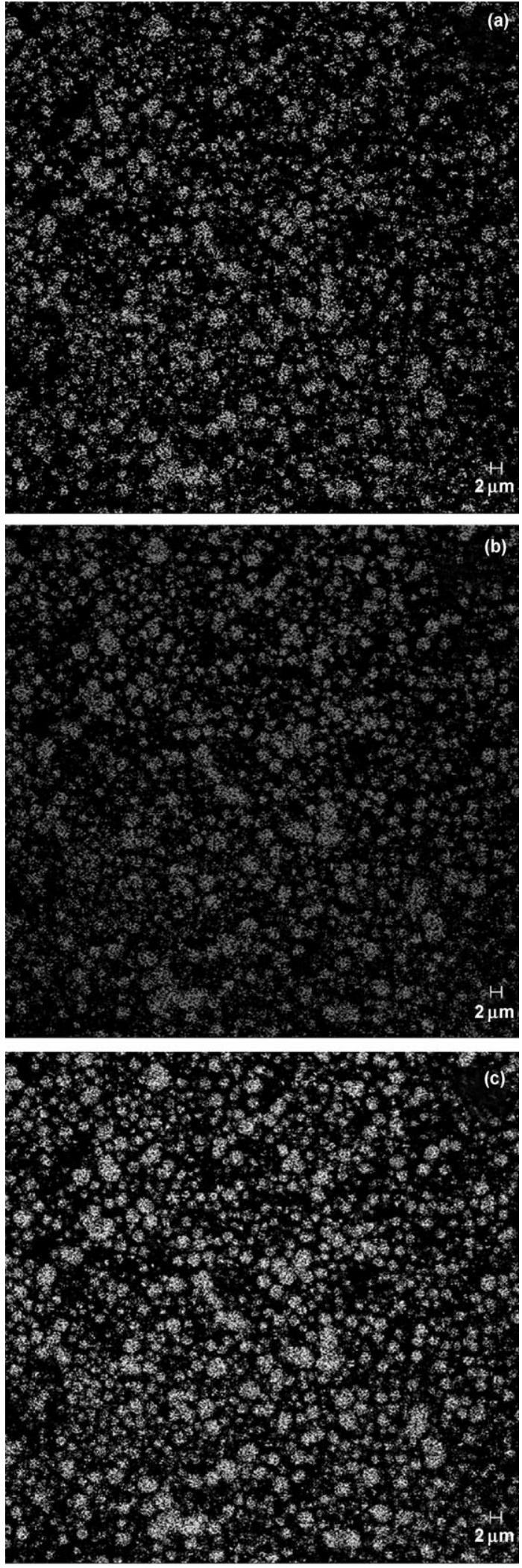

Figure 10. CLSM images of settled polymeric aggregates assembled from PEG350/EtTrp-PPP using DMF as organic solvent a) excited at $488 \mathrm{~nm}, \mathrm{~b}$ ) excited at $543 \mathrm{~nm}$, and c) an overlay of (a) and (b). copolymer PEG2000/EtTrp-PPP by tumor cells indicated that polymeric micelles assembled by this type of amphiphilic copolymer might be used as visible tracers to study the intracellular fate and other in vitro and in vivo processes of micelles and other nanoparticles. In addition, imaging of micro- or nanoparticles based on these fluorescent polyphosphazenes through multiphoton fluorescence microscopy of in vitro or in vivo studies will be carried out in our lab, and the related results will be published elsewhere.

\section{Experimental Section}

Materials: Hexachlorocyclotriphosphazene (Strem Chemicals) was purified by recrystallization from hexane and subsequent sublimation at $80-90^{\circ} \mathrm{C}$. N-isopropylacrylamide (NIPAAm) (Acros Organics) was recrystallized twice from hexane before use. $\mathrm{N}, \mathrm{N}$ Azobis (isobutyronitrile) (AIBN) was purified by recrystallization in a benzene/hexane mixture and in ethanol, respectively. 2-Aminoethanethiol hydrochloride (AET.HCl) obtained from Acros Organics was used as received. 4-Nitrophenyl chloroformate (97\%) was purchased from Acros Organics (Geel, Belgium). Monomethyl ether polyethylene glycol (MPEG) of various molecular weights $(350,1100$, and 2000) was purchased from Fluka Chemie GmbH (Germany). Ethyl tryptophan (EtTrp) was synthesized according to literature. ${ }^{[62]}$ Poly(vinyl alcohol) (PVA) $\left(M_{\mathrm{w}}=8\right.$, $8000,88 \%$ hydrolyzed) was purchased from Acros Organics (Geel, Belgium). Unless stated otherwise, all reagents and solvents were commercially available and dried just before use.

Polymer synthesis: Amino-terminated NIPAAm oligomer (PNIPAAm) was synthesized according to the literature. ${ }^{[21]}$ Monometh$y l$ ether PEGs with terminal amino group at the other end were synthesized by the method previously reported by Hoffman et al. ${ }^{[63]}$ Poly(dichlorophosphazene) was synthesized by thermal ring-opening polymerization of hexachlorocyclotriphosphazene in the presence of $5.0 \% \mathrm{AlCl}_{3}$ at $250{ }^{\circ} \mathrm{C} .{ }^{[19]}$ Amphiphilic polyphosphazenes with PNIPAAm or PEG and EtTrp as hydrophilic segment and hydrophobic group were synthesized according to our previously established method. ${ }^{[23]}$ Briefly, an appropriate amount of EtTrp was first introduced by nucleophilic substitution, and then excess amount of PNIPAAm or PEG were added to completely substitute all the $\mathrm{P}-\mathrm{Cl}$ bonds in polyphosphazene backbone. After precipitating from diethyl ether, copolymers were further purified by dialysis (MCWO:12 kDa) in distilled water and lyophilized. Hydrophobic polyphosphazene totally substituted with EtTrp was synthesized with the same procedure by using excess amount of EtTrp in the substitution reaction. Detailed synthesis procedure can be found in the Supporting Information.

Polymer characterization: FT-IR spectra were measured on a Bruker VECTOR 22 spectrometer. ${ }^{1} \mathrm{H}$ NMR spectra were recorded on an Avence DMX500 spectrometer at $20^{\circ} \mathrm{C} .{ }^{31} \mathrm{P}$ NMR spectra of polymers were acquired on Varian INOVA400 spectrometer in $\left[D_{6}\right]$ DMSO with no either external or internal standard employed. The molecular weight of all the polymers was determined using gel permeation chromatography (GPC) equipped with a Waters 515 HPLC Pump and a Waters 2410 refractive index detector. THF was used as eluent solvent with a flow rate of $1.5 \mathrm{~mL} \mathrm{~min}^{-1}$ 

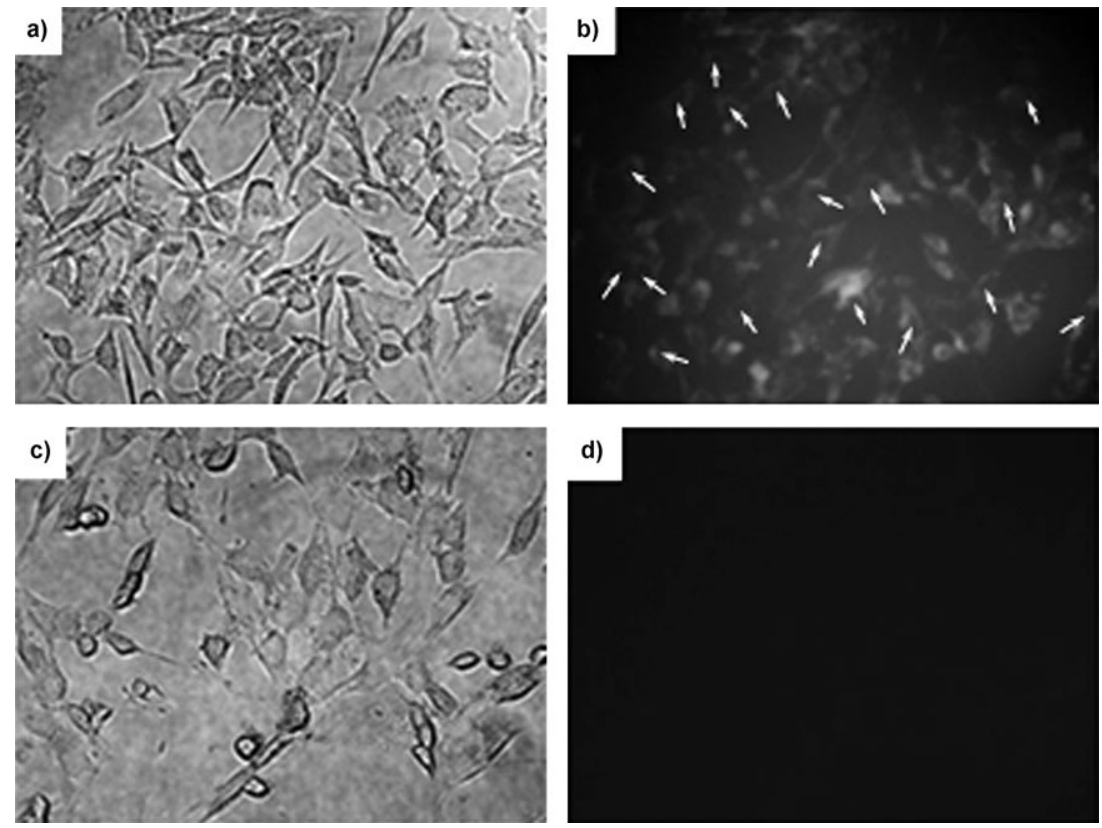

Figure 11. Intracellular uptake of PEG2000/EtTrp-PPP micelles by MG-63 tumor cells a) MG-63 cells were cultured in the medium containing $2.5 \mathrm{mg} \mathrm{mL}^{-1}$ PEG2000/EtTrp-PPP, bright-field image; b) excited with blue light, white arrows indicate the nucleus of MG-63 cells; c) control cells incubated in the medium without copolymer, bright-field image, and d) excited with blue light.

at $40^{\circ} \mathrm{C}$ and narrowly dispersed polystyrene as calibration standards. The molar content of EtTrp in copolymer was quantified by UV/Vis Spectrophotometer (TU-1800PC, Beijing Purkinje General Instrument Co., Ltd., China).

Fluorescence studies: 3D fluorescence spectra were acquired at $15^{\circ} \mathrm{C}$ on a fluorescence spectrophotometer (Hitachi F-4500, Japan). The slit width for excitation and emission was 5 and $10 \mathrm{~nm}$, respectively, and the scan speed was $12000 \mathrm{~nm} \mathrm{~min}^{-1}$. Fluorescence quantum yields, $\Phi$, were determined relative to Ltryptophan $\left(\Phi_{\text {Trp }}=0.14\right)$, using the relationship $\Phi / \Phi_{\text {Trp }}=\left(S / S_{\text {Trp }}\right) \times$ $\left(A_{\text {Trp }} / A\right)$, where $S$ is the integrated fluorescence intensity of the test sample and $A$ is its absorbance at the excitation wavelength. ${ }^{[32]}$ All the samples were measured in DMF, with an excitation wavelength of $280 \mathrm{~nm}$. The emission peak from 294 to $500 \mathrm{~nm}$ was integrated for the calculation of quantum yield.

CAC measurement: CAC of amphiphilic copolymer in aqueous solution was determined by a fluorescence probe technique. ${ }^{[64]}$ Sample solutions for CAC measurement were prepared as described previously. ${ }^{[64]}$ Steady-state fluorescent spectra were acquired using an F-4500 fluorescence spectrophotometer (Hitachi F-4500, Japan) with a slit width of $2.5 \mathrm{~nm}$ for both excitation and emission. For the fluorescence measurements, $1 \mathrm{~mL}$ of solution was placed in a $1.0-\mathrm{cm}$ square quartz cell. All spectra were run on air-equilibrated solutions. For fluorescence excitation spectra, the emission wavelength was set at $390 \mathrm{~nm}$. Spectra were accumulated with scan speed of $240 \mathrm{~nm} \mathrm{~min}^{-1}$.

Microparticle preparation: EtTrp-PPP-based microspheres were prepared by oil-in-water (o/w) emulsion solvent evaporation method using PVA as emulsifier. ${ }^{[49]} \mathrm{A}$ dialysis method was employed to prepare aggregates of amphiphilic copolymers that can not be directly dissolved into water, which including PNIPAAm/EtTrp-PPP-1, PNIPAAm/EtTrp-PPP-2, PEG350/EtTrp-PPP, and PEG1100/EtTrp-PPP. As for PNIPAAm/EtTrp-PPP-3 and PEG2000/EtTrp-PPP, polymeric assemblies were obtained by dissolving copolymer into water. Hybrid assemblies were prepared by dialyzing DMF solution containing both EtTrp-PPP and PNIPAAm/EtTrp-PPP-2 of different weight ratios in deionized water.

Microparticle morphology observation: TEM images were obtained using a JEM 1200EX operating at an acceleration voltage of $60 \mathrm{kV}$. Copper grids were precoated with a thin film of Formvar. Dialyzed or dissolved sample solutions were observed without further treatment. Samples for TEM were prepared at $15^{\circ} \mathrm{C}$ by dipping a copper grid into the copolymer solution, and extra solution was blotted with filter paper. CLSM images were taken with a Leica TCS SP Spectral Confocal Microscope (Leica, Germany) equipped with a 100 (or 20) x oil immersion objective.

Particle-size determination: The particle size of microspheres based on EtTrp-PPP was determined by coulter LS-230 laser particle size analyzer (Miami, America), while Dynamic Light Scattering (DLS) (90 Plus Particle Size Analyzer, Brookhaven Instruments $C_{0}$.) was adopted to measure the particle size of assemblies derived from amphiphilic copolymers.

Degradation study of EtTrp-PPP microspheres: Preweighed (about $10 \mathrm{mg}$ )EtTrp-PPP microspheres were dispersed in individual test tubes containing $1.0 \mathrm{~mL}$ PBS $(0.1 \mathrm{M}, \mathrm{pH}$ 7.4). The tubes were kept in an incubator maintained at $37^{\circ} \mathrm{C}$. At predetermined time intervals, the microspheres were collected by centrifugation, washed four times with distilled water, and lyophilized. The molecular weight was measured by GPC as described above. To evaluate the effect of degradation on polymer fluorescence, microspheres were also observed with fluorescence microscopy (Olympus CKX41) at specific time points.

Intracellular uptake experiment: Human osteosarcoma cell line MG-63 was purchased from the Institute of Biochemistry and Cell Biology (Shanghai, P.R. China). MG-63 cells were maintained in DMEM cell culture medium $\left(3 \times 10^{4}\right.$ cellswell $\left.^{-1}\right)$ supplemented with $10 \% \mathrm{FBS}, 50$ units $\mathrm{mL}^{-1}$ penicillin, and $50 \mu \mathrm{g} \mathrm{mL}^{-1}$ streptomycin, and incubated in a humidified atmosphere with $5 \% \mathrm{CO}_{2}$ at $37^{\circ} \mathrm{C}$ for $24 \mathrm{~h}$. The growth medium was replaced with fresh medium that contained the desired amount of micelles based on PEG2000/EtTrp-PPP. After incubation for $2 \mathrm{~h}$, the wells were washed twice with Hanks solution to remove micelles in culture medium, and then fluorescence microscopy (Olympus CKX41) was adopted to observe the intracellular uptake of polymeric micelles by MG-63 cells. 


\section{Acknowledgements}

Mr. Chunhu Yang in the Bioelectromagnetics Laboratory of Zhejiang University is acknowledged for his help on CLSM measurements. We are grateful to Prof. Ping Lu in the Department of Chemistry at Zhejiang University for valuable discussions on multiphoton excitation. Financial support from the National Natural Science Foundation of China (No.50203012) and the Zhejiang Natural Science Foundation (No.R204233) is gratefully acknowledged.

[1] S. M. Moghimi, A. C. Hunter, J. C. Murray, Pharmacol. Rev. 2001, 53, 283.

[2] M. Gumbleton, D. J. Stephens, Adv. Drug Delivery Rev. 2005, $57,5$.

[3] V. P. Torchilin, Adv. Drug Delivery Rev. 2005, 57, 95.

[4] N. S. White, R. J. Errington, Adv. Drug Delivery Rev. 2005, 57, 17.

[5] F. Delie, Adv. Drug Delivery Rev. 1998, 34, 221.

[6] Y. Li, H. L. Jiang, J. F. Jin, K. J. Zhu, Drug Delivery 2004, 11, 335.

[7] V. P. Torchilin, Cell. Mol. Life Sci. 2004, 61, 2549.

[8] M. A. Flynn, Y. Vodovotz, R. Kornowski, S. Epstein, D. Gordon, J. A. Keiser, BioTechniques 2000, 28, 470.

[9] L. C. Katz, A. Burkhalter, W. J. Dreyer, Nature 1984, 310, 498.

[10] J. J. Quattrochi, A. N. Mamelak, R. D. Madison, J. D. Macklis, A. Hobson, Science 1989, 245, 984.

[11] R. Madison, J. D. Macklis, C. Thies, Brain Res. 1990, 522, 90.

[12] F. X. Lacasse, M. C. Filion, N. C. Phillips, E. Escher, J. N. McMullen, P. Hildgen, Pharm. Res. 1998, 15, 312.

[13] A.V. Kabanov, V. I. Slepnev, L. E. Kuznetsova, E. V. Batrakova, V.Y. Alakhov, N. S. Melik-Nubarov, P. G. Sveshnikov, Biochem. Int. 1992, 26, 1035.

[14] D. Maysinger, O. Berezovska, R. Savić, P. L. Soo, A. Eisenberg, Biochim. Biophys. Acta 2001, 1539, 205.

[15] J. Liaw, T. Aoyagi, K. Kataoka, Y. Sakurai, T. Okano, Pharm. Res. 1999, 16, 213.

[16] L. Luo, J. Tam, D. Maysinger, A. Eisenberg, Bioconjugate Chem. 2002, 13, 1259.

[17] R. Savić, L. Luo, A. Eisenberg, D. Maysinger, Science 2003, 300, 615.

[18] S. M. Moghimi, A. C. Hunter, M. J. C. , A. Szewczyk, Science 2004, 303, 626.

[19] Y. S. Sohn, Y. H. Cho, H. Baek, O. S. Jung, Macromolecules 1995, 28, 7566.

[20] H. R. Allcock, T. J. Fuller, D. P. Mack, K. Matsumura, K. M. Smeltz, Macromolecules 1977, 10, 824.

[21] G. Chen, A. S. Hoffman, Nature 1995, 37349.

[22] J. X. Zhang, L. Y. Qiu, Y. Jin, K. J. Zhu, React. Funct. Polym. 2006, $66,1630$.

[23] J. X. Zhang, L.Y. Qiu, K. J. Zhu, Macromol. Rapid Commun. 2005, 26, 1716.

[24] A. Singh, N. R. Krogman, S. Sethuraman, L. S. Nair, J. L. Sturgeon, P. W. Brown, C. T. Laurencin, H. R. Allcock, Biomacromolecules 2006, 7, 914.

[25] V. P. Torchilin, Adv. Drug Delivery Rev. 2002, 54, 235.

[26] Y. Kakizawa, K. Kataoka, Adv. Drug Delivery Rev. 2002, 54.

[27] C. Allen, D. Maysinger, A. Eisenberg, Colloids Surf. B 1999, 16, 3.

[28] R. Swaminathan, G. Krishnamoorthy, N. Periasamy, Biophys. J. 1994, 67, 2013.
[29] A. S. Ladokhin, P. W. Holloway, Biophys. J. 1995, 69, 506.

[30] A. S. Ladokhin, Biophys. J. 1999, 76, 946.

[31] B. Sengupta, P. K. Sengupta, Biochem. Biophys. Res. Commun. 2000, 277, 13.

[32] M. R. Eftink, Y. Jia, D. Hu, C. A. Ghiron, J. Phys. Chem. 1995, 99 , 5713.

[33] R. Y. Tsien, Annu. Rev. Biochem. 1998, 67, 509.

[34] M. Aboubakar, P. Couvreur, H. Pinto-Alphandary, B. Gouritin, B. Lacour, R. Farinotti, F. Puisieux, C. Vauthier, Drug Dev. Res. 2000, 49, 109.

[35] A. S. Belmont, TRENDS Cell Biol. 2001, 11, 250.

[36] F. S. V. Wouters, P. J. Verveer, P. I. H. Bastiaens, TRENDS Cell Biol. 2001, 11, 203.

[37] M. Zimmer, Chem. Rev. 2002, 102, 759.

[38] D. S. Kohane, D. G. Anderson, C. Yu, R. Langer, Pharm. Res. 2003, 20, 1533.

[39] J. Wen, G. J. A. Kim, K. W. Leong, J. Controlled Release 2003, 92, 39.

[40] J. R. Lakowicz, Principles of Fluorescence Spectroscopy, Plenum Press, New York and London, 1983.

[41] J. R. Lakowicz, Nonlinear and Two-Photon-Induced Fluorescence, Vol. 5, Plenum Press, New York 1997.

[42] D. J. S. Birch, Spectrochim. Acta 2001, 57, 2313.

[43] J. R. Lakowicz, I. Gryczynski, E. Danielsen, J. K. Frisoli, Chem. Phys. Lett. 1992, 194, 282.

[44] I. Gryczynski, H. Malak, J. R. Lakowicz, H. C. Cheung, Biophys. J. 1996, 71, 3448.

[45] A. R. Rehms, P. R. Callis, Chem. Phys. Lett. 1993, 208, 276.

[46] D. T. Cramb, S. C. Wallace, J. Fluoresc. 1998, 8, 243.

[47] M. R. Eftink, C. A. Ghiron, Anal. Biochem. 1981, 114, 199.

[48] A. K. Singh, J. Das, J. Photochem. Photobiol. A 1998, 117, 119.

[49] J. X. Zhang, D. Chen, S. J. Wang, K. J. Zhu, J. Microencapsulation 2005, 22, 413.

[50] J. X. Zhang, K. J. Zhu, D. Chen, J. Microencapsulation 2005, 22, 117.

[51] H. R. Allcock, Science 1976, 193, 1214.

[52] H. R. Allcock, S. R. Pucher, A. G. Scopelianos, Biomaterials 1994, 15, 563.

[53] F. M. Veronese, F. Marsilio, S. Lora, P. Caliceti, P. Passi, P. Orsolini, Biomaterials 1999, 20, 91.

[54] M. Gümüşderelioğlu, A. Gür, React. Funct. Polym. 2002, 52, 71.

[55] S. Lakshmi, D. S. Katti, C. T. Laurencin, Adv. Drug Delivery Rev. 2003, 55, 467.

[56] J. X. Zhang, L. Y. Qiu, Y. Jin, K. J. Zhu, Macromolecules 2006, 39, 451.

[57] Y. Geng, P. Dalhaimer, S. S. Cai, R. Tsai, M. Tewari, T. Minko, D. E. Discher, Nat. Nanotechnol. 2007, 2, 249.

[58] C. W. McCutchen, J. Opt. Soc. Am. 1967, 57, 190.

[59] D. R. Sandison, R. M. Williams, K. S. Wells, J. Strickler, W. W. Webb, Handbook of Biological Confocal Microscopy Plenum Press, New York 1995.

[60] J. X. Zhang, X. D. Li, M. Q. Yan, L.Y. Qiu, Y. Jin, K. J. Zhu, Macromol. Rapid Commun. 2007, 28, 710.

[61] N. Nishiyama, K. Kataoka, Pharmatherapeutica 2006, 112, 630.

[62] M. Dymicky, E. F. Mellon, J. Naghski, Anal. Biochem. 1971, 41, 487.

[63] A. S. Hoffman, G. Chen, Int. Pat. Appl. WO 95/24430, 1995.

[64] M. Wilhelm, C. L. Zhao, Y. Wang, R. Xu, M. A. Winnik, Macromolecules 1991, 24, 1033.

Received: January 29, 2007

Published online on November 22, 2007 